\title{
Shaping the female student: an analysis of Swedish beauty school recruitment texts
}

\author{
Eleonor Bredlöv
}

\section{Linköping University Post Print}

\section{Tweet}

N.B.: When citing this work, cite the original article.

This is an electronic version of an article published in:

Eleonor Bredlöv, Shaping the female student: an analysis of Swedish beauty school recruitment texts, Studies in Continuing Education, 2016 38(2), pp. 243-258.

Studies in Continuing Education is available online at informaworldTM:

http://dx.doi.org/10.1080/0158037X.2015.1113165

Copyright: Taylor \& Francis (Routledge): SSH Titles

http://www.routledge.com/

Postprint available at: Linköping University Electronic Press

http://urn.kb.se/resolve?urn=urn:nbn:se:liu:diva-129785 


\section{Shaping the female student: an analysis of Swedish beauty school recruitment texts}

Eleonor Bredlöv*

PhD student, Department of Behavioural Sciences and Learning, Linköping

University, Linköping, Sweden

Full reference: Bredlöv, E., 2016. "Shaping the female student: An analysis of Swedish beauty school recruitment texts.” Studies in Continuing Education 38(2): 243-258.

\footnotetext{
*Email: eleonor.bredlov@liu.se, Address: Linköpings universitet, 58183 Linköping, Telephone number: +4613284496
} 


\title{
Shaping the female student: an analysis of Swedish beauty school recruitment texts
}

\begin{abstract}
This study focuses on the recruitment of adults to the beauty industry in Sweden. It is concerned with a move in (beauty) education away from state and towards private provision in a wider context where education is becoming more heavily marketised. Drawing on a poststructural approach inspired by the work of Foucault and feminist theory, the shaping of student subjectivity in recruitment material for private beauty schools is analysed. A poststructural approach provides analytical tools that make visible the process of how power shapes subjectivities, and the use of feminist theory gives special focus to the gendered aspects of this process. The study includes a textual analysis of website homepages of beauty schools, beauty schools' Facebook pages and web pages that provide compiled information on educational programs and courses connected to the beauty industry. The analysis shows how consumption is constituted and feminized through specific marketing strategies and thereby becomes both a starting point and a resource for the shaping of student subjectivity. Thus, a particular form of gendered entrepreneurial self is shaped in this femininised educational context, and this study therefore highlights the importance of vocational research that takes into account the shaping of student subjectivity.
\end{abstract}

Keywords: adult education; recruitment; beauty industry; subjectivity; poststructural feminism

\section{Introduction}

This article explores the processes through which student subjectivity is shaped in recruitment within the frame of marketising an educational system, more specifically, private schools connected to the beauty industry in Sweden. Beauty education is an unexplored field of research, and the beauty industry has shown remarkable growth internationally, with a growth rate that has tripled over the last twenty years. The industry continues to grow steadily and is relatively resistant to economic crises (Jones, 2010). This growth is also noticeable in the education sector in Sweden, where new unregulated private beauty schools are being established.

In order to understand the key issues at play in the development of the beauty education market, the context of adult vocational training and education in Sweden needs to be outlined. The public adult education system in Sweden consists of adult education (komvux), adult education for the intellectually disabled (särvux) and Swedish for immigrants (sfi). Local municipalities fund these educational programs and courses, and adults can partake in them at no cost. It has been government policy to recruit adults who have limited educational achievements and experience, and efforts have been made to further involve these groups in education. Therefore, recruitment processes have been an important theme in adult education research (see, e.g., Cross, 1981; Boshier, 1973; Rubenson, 1975; Hult et al, 1997; Paldanius, 2002; Hult, 1997; Lundquist, 1989; Cookson, 1989; Owens, 2000). Recruitment research has primarily addressed why some adults choose to participate in education and some do not (Cross, 1981: Boshier, 1973; Rubenson, 1975: Mäkitalo et al, 1997). A significant part of this research engages with the difficulties of enrolling people with limited educational achievements and experience in educational programs (Paldanius, 2002; Hult, 1997) and with developing methods for engaging adults who are difficult to recruit. Lundquist (1989) and Rubenson (1975) have, for example, investigated the factors that are perceived to motivate prospective participants, as have studies that focus on developing strategies to encourage groups with low education levels to undertake different types of educational courses and programs (Long, 1983; Cookson, 1989). Many of these studies investigate barriers preventing less educated groups from participating in adult education (Cross, 1981; Owens, 2000). 
However, with the current marketisation, decentralisation and deregulation of the Swedish educational system (Lundahl, 2010), new recruitment practices for adult students have emerged, partially changing the target of such practices. In line with this development, rather than funding education and delivering these courses themselves, some municipalities invite tenders for educational provision. After receiving bids from several different stakeholders, the provider that can offer the best price in relation to quality is contracted for two to three years at a time. This policy creates competition between multiple educational providers, whose activities can only be planned in the short-term. In some municipalities, several providers are tendered at the same time, and several providers are often contracted to deliver the same program and courses, which creates a situation in which these providers must compete for the same students. As an effect of this development, adult education providers must now market themselves or make an attractive offer in relation to the municipalities' tendering processes so that they receive educational assignments; in some cases, they must also market themselves directly to students. The marketisation of education in Sweden has created new recruitment practices within adult education, in which educational providers must engage in marketing activities.

Marketisation and competition between adult educational providers has emerged to an even greater extent in relation to the beauty industry, where there is a plurality of stakeholders operating in a free market. While there are some publicly funded courses for the beauty industry within municipal education, the largest share of the market is comprised of schools that charge fees to students, resulting in different recruitment practices. Rather than recruiting those with low levels of education, students who might become interested in working in the beauty industry and can pay for themselves have become the target group. The marketing of an educational provider plays a crucial role in the process of corporate image and identity construction (Evangelisti Allori and Garzone, 2011, 10). The goal of the educational provider is to portray itself as a company selling products desired by the target group, in this case, potential students. Additionally, the company has the opportunity to dictate conditions for how students can be successful and operate in this sphere. Thus, within the marketing activities of private beauty schools, marketing shapes not only the corporate image but also student subjectivity in particular ways.

As earlier research has shown, boundaries between leisure and work have, in recent years, become less distinct (Lewis, 2003) and people make certain lifestyle choices in order to shape themselves into becoming appropriate workers in a specific vocation or profession (Waring, 2008). Especially in service occupations, these choices extend to the emotional life of the worker (see Hochschild, 1983). In the light of this development it is important to examine how student subjectivity is shaped in recruitment to a specific private vocational school. In Sweden, both the marketisation of adult education and the recruitment of adult students within the beauty industry are unexplored fields of research, which further underlines the importance of this study.

Drawing on the work of Foucault and tools provided by feminist poststructuralist theorisation on subjectification processes, my aim in this article is to analyse how student subjectivity is shaped within these new recruitment practices emerging in the wake of the marketisation of adult education in Sweden. As a starting point, I focus on the marketing activities of beauty schools.

\section{Beauty schools in Sweden}


The beauty business is multifaceted and difficult to define, as everything from cosmetic surgery to fitness practices can be included. However, Statistics Sweden's ${ }^{\dagger}$ definition of 'beauty treatments' includes spa treatments, skin therapy, practices in beauty salons and nail salons, makeup and hair styling. This definition provides guidance to how the beauty industry is defined in this article. It is also important to note that product sales is an important activity in spas and salons and that it is common for students graduating from these schools to obtain work in the beauty sections of department stores, for example.

Courses and programs for learning vocations for the beauty industry are not government funded, apart from a few exceptions on an upper secondary school level, and participants must pay a fee, which differs depending on the type of course or program and the program's length. For instance, an educational program for becoming a 'skin and spa therapist', at 57 weeks long, costs approximately $98000 \mathrm{SEK}^{\ddagger}$, a ten-week course in 'nail therapy' costs approximately 43000 SEK, and a ten-week course in 'makeup' costs approximately 34 000 SEK.

There are no formal study plans or guidelines on a national level - these types of courses and programs are unregulated. However, schools often cooperate with various trade organisations that are said to oversee the school activities, assuring that the education meets the demand of future employers. The companies running these schools also most often cooperates with different types of businesses in the beauty industry, such as spa facilities and product brands, and sometimes these companies also run a spa facility, a salon, an agency for beauty workers and/or a product brand, alongside running the school. The private beauty schools are by far the largest providers of adult education connected to the beauty industry in Sweden, and the expansion of these types of schools further underlines the importance of research in this area.

Girls and women have dominated the beauty industry in Western societies as both customers and employees (Jones, 2010), and these vocations mobilise practices aimed at changing and correcting people's appearance. Thus, normativity regarding beauty and looks is produced through these practices - practices that can be viewed as gendered practices. Moreover, the people performing these practices, beauty workers, are also constructed in a gendered way. As literature about the beauty industry notes (Jones, 2010; Black, 2004; Scranton, 2001; Gimlin, 1996), the beauty worker is constructed through femininity, although fashion and beauty products are also increasingly becoming linked with men (Nordberg, 2005; Edwards, 1997). However, because student subjectivity is primarily shaped as feminine in particular ways in the examined text of this study, the concept of femininity is central in the analysis of how subjectivities are shaped and how gender plays a role throughout this process.

\section{Theoretical approach and empirical material}

To understand the ways in which beauty school student subjectivity is shaped, I draw on a poststructuralist perspective inspired by Michel Foucault (1980, 1988, 1990, 2007) and feminist theory (McNay, 1992; Ramazanoglu, 1993). The Foucauldian resources enable me to analyse how student subjectivities emerge through the recruitment material and the different ways these are positioned through discourses. Because these subjectification processes occur in a highly femininised setting, one major focus lies on the specific processes around constructions of femininity. Therefore, I draw on the writings of feminists

\footnotetext{
† An administrative agency that provides statistics for decision-making, debate and research. Statistics Sweden is primarily assigned these tasks by the government, but also by the private sector and among researchers (http://www.scb.se/en_/About-us/).

‡ 1 SEK comes to 0,10 Euros, 2015-08-21
} 
whose work discusses the implications of the crossover between feminist thought and the resources of Foucault. These writings allow me to analyse how student subjectivities emerge in beauty school recruitment in particular ways through taking constructions of femininity into account.

A common understanding of participants in educational settings draws on liberal humanist values, where students and teachers are seen as autonomous individuals who have the freedom to choose what type of person to be, even if this freedom comes in various degrees (Davies, 2006). A poststructuralist approach can provide different insights into the sphere of education and provides analytical tools that make visible the process through which power shapes subjectivities. Drawing on Foucault, power is here understood as productive and can also be perceived as a positive force, operating relationally and making possible the emergence of certain subjectivities (Foucault, 1980). This power is multiple, and subjectivity is seen as fragmented and shaped discursively, thereby shaped by language in particular ways. This approach allows the subject to adopt several positions through discourse, allowing an analysis in which subjectivity becomes multiple subjectivities. Nevertheless, subjectivities can adopt a particular shape through the regularities of discourse. Thus, certain language allows certain subjects to be shaped, subjects that are positioned through particular locations in power-knowledge regimes - what we say and how we view ourselves can be explained in relation to what is discursively available to us (Foucault, 1990). Through such an approach, people become both the products and the producers of discourse (Foucault, 1980, 2007).

My combination of resources from the work of Foucault and feminist theory entails an analysis centred on the assumption that gender is a starting point for power relations. Gender relations are here seen as historically specific effects of power. These effects are constituted by changeable social forces rather than by our fixed, physical being (Ramazanoglu, 1993, p. 6). Along these lines, I adopt the view of the body as shaped through power relations - the body as a product of multiple processes of power (Foucault, 1990). Such a conception includes the assumption of how, for example, female experiences are shaped through controlling images of feminine sexuality. Accordingly, the body is disciplined through a multiplicity of power relations - for instance, through controlling images of femininity (McNay, 1992) and the technologies of power that we ourselves practice on our bodies (Foucault, 1988). These practices include pampering, correcting, grooming and putting on makeup, which are common practices within beauty work.

The data collection focused on the information channels available to prospective students online, which corresponds well with the aim of the study, which is to analyse how student subjectivity is shaped through discourses emerging in the recruitment material. Included in the examined texts are web pages that provide information on various educational programs and courses. This information often includes positive student reviews selected by the schools for marketing purposes. These web pages connected me to the homepages of each school, as well as to each school's Facebook page when they were available. These are web sites that prospective students browse in their quest to choose a school, educational program, or course or to decide whether they want to partake in this type of vocational education in the first place. In total, the homepages of 36 schools have been analysed as well as 14 schools' Facebook pages.

The schools offer self-contained educational programs for becoming a 'skin therapist,' 'beauty therapist,' 'makeup artist' or 'nail therapist'. In addition, the schools also offer detached, shorter courses in, for example, 'make up special effects,' 'hair extensions,' 'lashes and eye brows,' 'wax' and 'massage.' A poststructuralist framework enables an analysis in which all forms of meaning production in the recruitment material, including 
pictures, aesthetics, interaction via social media, job ads, product advertisements, student reviews, special offers and other occurrences, are viewed as text (Derrida, 1991).

\section{Analysis}

In the following, my analysis of the recruitment text will be presented, in which regularities of discourse have been identified. Three themes emerge in these regularities: first, how student subjectivity is shaped through responsibilising and individualising processes; second, how the student is shaped as a buyer and a seller in specific ways; and third, how boundaries between leisure and work/school are blurred in the text, a theme that cuts through the two previous sections. The quotes presented are selected as exemplars of the three main themes emerging through regularities of discourse identified in the wider research analysis. The paper ends with a discussion of the main results.

\section{The responsible beauty student}

The examined text constructs a responsible student who should be independent and competitive and who enters into the education market with freedom of choice and a strong desire to evolve and achieve her goals. Moreover, the successful student is constructed as feminine, loyal and blessed with talent. In the following quote, found at a beauty school homepage, the question of choosing a specific educational program is raised*:

When you have decided on becoming a nail therapist, it is very important that you choose your educational program carefully, because it is your future that is at stake!

The 'you' being addressed here, that is, the prospective student, is given the responsibility of choosing the right educational program. The importance of choosing is carefully underlined with the statement that the future of the addressed 'you' is at risk. A statement such as that above is part of a course of events in which student subjectivity is shaped through individualising processes and in which the student is constructed as a participant in the market for education, free to make her own choice yet responsible for making the right one. Responsibilising and individualising processes are also noticeable in the following quote, which is found at a web site that provides information on available programs and courses. It is a statement from a former (or contemporary) student in a school for skin therapists, as a part of a (positive) school review selected by the school for marketing purposes:

\footnotetext{
I had a really great time during the entire course: we were just a few girls participating at that time (...) My advice to you as a student-to-be is to not lose focus on what it is that you want and to work towards this at all times, even if it is hard sometimes. You set the limit for what is possible!
}

Here, a former (or contemporary) student passes on her knowledge to prospective students in the form of advice. The course, and maybe also this line of work, is described as tough but with a window of possibility, where success is reachable if you just put your mind to it and work hard. Thus, student subjectivity is shaped through individualising processes, in which the individual is given full responsibility for his or her failure or success. By stating that 'we were just a few girls participating,' this specific student shapes herself and her fellow students through constructions of femininity - something that is visible throughout the examined text.

The following quote is an example of how student subjectivity is shaped in responsibilising ways through descriptions of future work opportunities:

\footnotetext{
* All quotes have been translated from Swedish by the author
} 


\begin{abstract}
Work opportunities
Naturally, we cannot promise you employment after the course. You need a lot of talent, willpower, practice and some sharp elbows in order to succeed. You have to make an effort to take initiative and show yourself off. With our diploma and good grades, you have a good chance of being able to support yourself in this well-paid line of work. We also have the opportunity to help our students after their course or program, and we are doing our best to provide as many work opportunities as possible to students who have shown that they are capable, reliable and loyal and have the talent and the willpower to succeed in this business.
\end{abstract}

Work opportunities are here described as dependent on the student's individual properties, actions and capacity to conform. The demand that students take initiative and show themselves off, together with the properties of having sharp elbows and a lot of willpower, construct the student as competitive and thereby also construct these educational settings as competitive. Moreover, students that are reliable and loyal have a greater chance of succeeding, positioning student subjectivity as belonging to, and being dependent on, the organisation. Being loyal and reliable in the eyes of the company is presented as crucial to whether the student has the potential to succeed in this business. As Rose (1996; 1999a; 1999b) argues, a responsibilising technology of the self has been found to be a distinctive feature of contemporary neoliberal governance and education practices. This involves a simultaneous process of responsibilisation and autonomisation (Rose, 1999b, 476; Fejes, 2010). This double movement is also illustrated in the following quote, which is found at a web site that provides information on available programs and courses. It is a statement from a former (or contemporary) student in a school for skin therapists, as a part of a (positive) school review selected by the school for marketing purposes:

It is a tough educative year where you just have to bite the bullet and focus on the goal. There are only women at the school and this can be tough from time to time, and this atmosphere is also reflected in the teachers. I mean, it is about looks. Be prepared to devote a lot of energy and time to school, but do not forget to have fun!

Here, the responsibilising and individualising process is operationalised in the shaping of femininity through the representation of feminine spaces as tough and filled with rivalry. Through this representation, femininity in this educational sphere is also shaped through the importance of looks, which is highlighted as central to the competitive atmosphere. This shapes student subjectivity in terms of self-awareness.

The quotes in this section are offered to illustrate how the responsible student emerges in the wider analysis. Thus, regularities of discourse suggest that the student is shaped as an autonomous, feminine individual who is responsible for her own learning, success and failure. She is competitive, she has clear goals, and she is prepared to adopt a tough attitude to reach these goals. She is also addressed as a consumer in the market for education, which is an aspect that I will elaborate on in the following section.

\title{
The student as buyer and seller
}

The activity of choosing and 'buying' a course or program initially shapes the student as a consumer, and as I have shown above, the student is shaped as a consumer of education in particular ways. In the following, I will also show how the student is shaped as a consumer of and salesperson in the beauty industry itself. The text is imbued with information on different tools, products and treatments, which constructs the student as a seller and marketer of these items and services while simultaneously being a buyer and user of these products. The quotes presented in the following have been selected as exemplars of how 
the beauty student as a buyer and a seller emerges in the wider analysis. The quotes derive from a range of different school homepages and Facebook pages.

The students of private beauty schools pay a course fee, for example 98000 SEK for a six month course in 'beauty therapy.' Other titles for courses include 'skin therapy,' 'makeup' and 'hair styling.' Costs for products are included in this fee and amount to approximately one-third of the total course fee. The products are used in class, and sometimes, the students are offered extra products for themselves as 'special offers.' Thus, the participants are expected to buy these types of products for their own private use. Many courses and programs are also sponsored by a brand, or schools have different types of partnerships with companies that sell beauty products. These relationships are illustrated in the following quote, which was found on a beauty school homepage:

\begin{abstract}
Product package
Makeup artists often have a special interest in colour, form and fashion, and this makes following current trends natural. This results in many makeup artists wanting to further develop in their vocation by trying new products, materials, colours and tools. The course price includes a package of products and tools, at a value of 15000 - 25 000, depending on the course chosen. Most students usually want to expand their makeup bag, though, by buying additional colours and tools. Therefore, all students get a personal makeup artist card that entitles them to a 30\% discount on the Mist Stockholm Line. In addition, students get special offers for buying certain products at a favorable price during the course. We recommend that students have additional resources during the course so that it is possible to buy more products if desired. Our students usually spend around 55000 SEK buying products and tools.
\end{abstract}

Here, student subjectivity is shaped through assumed interests (in colour, form and fashion) - interests that are linked to the specific consumer behaviour of buying beauty products and tools to develop as a successful makeup artist. This consumer behaviour can be viewed in terms of responsibly shaping one's life through acts of choice, in this case, choices of consumption.

Here the analysis shows clear indications of what we have come to understand through the work of Rose and others (Rose, 1999a; 1999b; 1996; Edwards, 2002) as the shaping of the entrepreneurial self - a dominant way of constructing the self in Western democracies. Operating within a neoliberal discourse, the relationship that is established with one's self is established through an 'enterprise form' that is generalised to all forms of conduct (Rose, 1999a). The relation to the self as an entrepreneurial self then becomes the basis for a number of investment decisions concerning, for example, education, employability and one's appearance. Responsible consumption is something that is particularly central in the shaping of subjectivities, where certain cultural values and norms constitute a starting point in the shaping of conduct, and individuals are taken as active subjects (Edwards, 2002, 357).

However, the student is also shaped as a consumer in far less responsibilising ways. In choosing (and buying) an educational program or course, the student is exposed to a variety of selling arguments that shape subjectivity in different ways. In the following quote, from another skin therapy school homepage, the selling argument is tied to the possibility of mixing business with pleasure:

Our education and training programs are held in the largest spa and conference hotels in the centre of Tallinn. (...) Combine your education and training with a wonderful SPA experience in Tallinn, for example, at Aqua Spa. Pamper your body and soul at the 
new and luxurious Aqua Spa! Aqua Spa offers you the opportunity to enjoy different types of saunas and swimming pools (...). Everything that you have been dreaming of is here!

Here, prospective students are tempted to choose this particular school through its exhortation to treat themselves to a visit at the spa. The quote is an example of how prospective students are addressed with the assumption that they are capricious consumers driven by their emotions and dreams. It also constructs pampering activities, related to desire and vanity, as creating a sense of luxury and a focus on the self (Little, 2013; Black, 2004). This construction has become viewed as an important component of the bodily maintenance and health of women in particular (Little, 2013). This example demonstrates how bodily activities are constructed in the text - bodily activities that prospective students are expected to engage in and desire.

Furthermore, the examined text is imbued with pages presenting products and brands in ways similar to their presentation in advertisements in popular media. The following quote is an example of a typical product ad found on yet another beauty school homepage:

\begin{abstract}
Golden Legs - 24 Karat Gold for perfect legs
It is finally possible to easily shape your legs to perfection, to become silky and hide varicose veins, scars and rashes. A new trend has arrived - Golden Legs - makeup for the legs! Golden Legs contains 24 karat pure gold for beautiful gold shimmering reflections. (...) The legs get a fantastic colour and become wonderfully soft, smooth and sensual.
\end{abstract}

This ad addresses the receiver based on the assumption that she is engaged in following new trends and articulates a vain, narcissistic shopper endeavouring to become 'sensual.' The quote illustrates the role of product ads in the process of shaping student subjectivity through the presumed and encouraged activities of bodily maintenance and implied consumer behaviour. However, information about products, tools, treatments and different brands also indirectly shape students as sellers and marketers because they are expected to make use of this type of information in their future vocational practice. Knowing how to make sales is presented as an important component of becoming a successful 'skin therapist' or 'beauty therapist,' a skill that emerges in descriptions of course contents. Some of the skills construed as being necessary to becoming a successful salesperson are social skills and being service-minded. This aspect becomes visible in the following quote, which is a text from a web page describing the arrangement of a program for becoming a skin therapist:

In the first six months, you will learn the basics of skin and body care (...). During the following six months, it is time to meet clients, and you will develop your skills related to techniques, customer service and sales.

Here, sales skills and successful customer service skills are proposed as important for the process of becoming a skin therapist.

The examined text also construes the prospective student as a seller through different marketing techniques. Two examples illustrate this point. First, there are 'special shopping nights' arranged by different brands in collaboration with the schools, to which students are invited and also encouraged to bring friends. During these events, the participants have the opportunity to shop at reduced prices and learn about new products. These shopping nights are an example of how students are shaped as marketers by the exhortation to bring friends. Second, the schools' Facebook pages mobilise a seller subjectivity. The following quote is a status update from the Facebook page of a private beauty school: 
Everybody can have beautiful and long lashes! We are raffling off a course in eye lash extension. The only thing you need to do is to like our page and then like and share our status update. No prior knowledge is necessary. Good luck!

Here, the student or prospective student has a chance to win a course if he/she helps to market the school. Another school that offers courses in makeup and styling also has a contest on Facebook. The participants - students at this particular school - all style and makeup friends according to a set theme, for example, 'dramatic' or 'trendy.' All participants post a picture of their efforts on Facebook, and whoever has the most 'likes' before the set date is the winner. The prize is a day with a model and a photographer and a number of extra pictures for their portfolio. Thus, to have a greater chance at succeeding, the students should do their best at marketing their school - as well as themselves.

Thus, the student is also shaped as a seller, a service-minded person with great social skills, who is also successful at marketing the school, brands and products as well as themselves. At the same time, the student is shaped as a responsible consumer of education and as a capricious female consumer of products and treatments. The consumption promoted here entails particular bodily activities that extend to one's leisure time. These images illustrate how student subjectivity is shaped through the blurred boundaries between work/school and leisure, which is a regular occurrence throughout the text that will be elaborated on in the next section.

\section{Blurred boundaries between work and leisure}

Selling arguments and other statements with references to pampering, shopping, putting on makeup, styling one's hair, engaging in facial and body treatments, etc., are a part of a process in which student subjectivity is shaped through embodiment during recruitment. Bodily activities imply certain necessary consumer behaviours that students partake in, both outside and inside of school. Embodiment illustrates how the blurred boundaries between leisure time and time for work or school are made visible through the analysis of the text, a theme that cuts through the two previous sections. I will reconnect with the previous sections as I show how the blurred boundaries between work/school and leisure emerge in the shaping of student subjectivity.

As earlier research has shown, boundaries between leisure and work have, in recent years, become less distinct (Lewis, 2003). Consistent with the concept of 'the entrepreneurial self,' the theoretical concept of 'workstyle' has been introduced in opposition to the term 'lifestyle,' which symbolises a person's individual choice in leisure activities (du Gay, 1995). Workstyle instead conveys how the influence of work on identities has intensified, and in the endeavour of shaping a desirable identity, individuals in different vocations and professions make certain lifestyle choices to develop an appropriate workstyle (Waring, 2008). The process of developing a workstyle shapes beauty student subjectivity, including activities of bodily maintenance as well as the consumer behaviour that these activities imply.

However, the process of adopting the right workstyle is primarily represented in reverse in the examined text, where the student's expected leisure activities are described as being put to good use in their working life through choosing education and training in connection to the beauty industry. Statements in which the student is addressed as someone with certain interests and leisure activities, as shown in the previous sections, operationalise a productive power in the shaping of student subjectivity and encourage a particular behaviour for an increased chance of success. In presenting these types of vocations, especially in former student reviews, expressions of the chosen vocation as a hobby are common. An example of this expression is found in the way a former student speaks about her work: 'I feel so lucky because I get to do my hobby as a job. It is a dream come true!' 
Making your hobby your job is making money from an activity that you would engage in even if you had a different vocation.

Moreover, the examined text consists of other aspects that shape student subjectivity through embodiment within beauty work. Pictures of smiling students, former students and teachers shape student subjectivity - and beauty worker subjectivity, for that matter - as groomed, healthy, happy, made-up, young, white, conventionally beautiful and feminine. These pictures illustrate how the shaping of student subjectivity mobilises power and constructs social categories, as well as how the shaping of student subjectivity extends to students' emotional lives. The beauty student has, as shown in a previous quote, been shaped through the activity of having fun. The following quote, taken from a job ad on a beauty school's Facebook page, is an example of how the emotion of joy is constructed as an important feature of a skin therapist:

\section{Right now, $\mathrm{X}$ is looking for happy, active skin therapists with experience in the} beauty business.

Skin therapists and skin therapy students are here shaped through the desirable properties of being happy and active. Thus, the construction of an appropriate beauty student workstyle not only includes certain bodily activities and individual properties but also extends to the student's emotional life, which includes a process of embodiment. This embodiment can be connected to gender constructions in which femininity is shaped through concepts of women as always emotionally available. The shaping of student subjectivity through the demonstration of an emotion, in this case, the emotion of joy, can also be connected to the notion 'emotional labour,' coined by Hochschild (1983) in her study on American flight attendants. Hochschild shows how workers' feelings and expressions of joy become products, which then come to belong more to the organisation than to the self (Hochschild, 1983, 198). In relation to writings on the entrepreneurial self, one could say that the skin therapy student is shaped through the desired emotion of joy which can be viewed as a product of a rational choice made by an active subject (Rose, 1999a; Edwards, 2002).

Blurred boundaries between leisure and work/school are also highly visible on the Facebook pages of beauty schools. Currently, new technologies, of which social media is a product, blur the lines between leisure and work/school and between the private and public spheres. Before the development of social media, private information was highly segregated, but now this type of information has become accessible to employers, colleagues, recruiters and clients (Sánchez et al., 2012). In my example, Facebook pages can be said to provide opportunities for the students to network and, as shown above, to receive information about work opportunities. Facebook also constitutes a platform for the marketing of the self, as in the example of the styling and makeup contest described above, and for the marketing of schools, products and treatments. All of these occurrences also work to govern the shaping of student subjectivity. Students are encouraged to 'like' and 'share' status updates and 'like' the school page, as well as to post pictures on the school page's 'wall.' These activities then end up in the news feeds of students' Facebook friends. Through these events, students are shaped as marketers, and this also shapes student subjectivity as belonging to the organisation - something that is reinforced by the shaping of the student as loyal and reliable.

Thus, several different processes shape the student through the blurred boundaries between leisure and work/school. A process of embodiment puts demands on students' everyday lives, where the consumption of beauty products and the bodily activities connected to these demands must take place. Moreover, a process of embodiment is highly visible in pictures found within the recruitment text, which shape normativity in relation to 
whiteness, age, function and gender. The repeated representation of the student as happy illustrates how normative exhortations are extended to students' emotional lives, thus making the boundaries between private and public and between work and leisure more porous. 'Boundary-crossing' is also constructed through representations of beauty therapists making their hobby their job, a hobby they would engage in regardless. In the parts of the text that constitute social media, students are invited to be active within the school's page and the occurrences there.

\section{Discussion}

The aim of this article has been to outline the shaping of student subjectivity in the recruitment process of private beauty schools. Drawing on Foucault, I view subjectivities as shaped by language in particular ways. In this process, power operates relationally, making possible the emergence of certain subjectivities. Thus, certain language allows certain subjects to be shaped, subjects that are positioned through particular locations in power-knowledge regimes. So, what we say and how we view ourselves can be explained in relation to what is discursively available to us (Foucault, 1990). I have shown how student subjectivities are shaped in gendered ways through neoliberal discourses in which the student is constructed through responsibilising and individualising processes. It is important to note here that at the very same moment at which the student is responsibilised for her success or failure, responsibility is being withdrawn from the educational company. I have also illustrated how the sought-after properties and presumed consumption and marketing activities shape the student as a seller and marketer of the very products and treatments she is encouraged to buy and use and which she is presumed to desire. A theme that cuts through the examined text is how the student is shaped in ways that blur the boundaries between leisure and work/school. These boundary-crossing processes emerge in different ways, such as through several processes of embodiment, through the shaping of the specific vocation as a calling and through activities in social media, where the student is shaped as a seller and marketer.

If previous studies on recruitment in adult education have primarily focused on recruiting less-educated groups and related issues such as hindrances to educational participation, my focus has been on how subjectivity is shaped in the marketing materials used to recruit students who construe themselves as motivated to participate in beauty education and potentially become a beauty worker. Thus, my study has provided results that are both different and complementary to prior research, and it has also provided insight into how femininity is made a central issue in recruitment activities.

Taking the notion of the entrepreneurial self into account, constructions of the beauty student as a consumer may appear to be paradoxical. On the one hand, the beauty student is positioned as a calculating, rational actor, operating within a market for education and within a specific labour market, expected to face the expressed demands to succeed, and responsible for her own failure or success. At the same time, student subjectivity is also shaped in far less responsibilising ways, through articulations addressing prospective students as capricious, vain consumers driven by their hopes and dreams - articulations that are filled with feminine connotations. As previous research (e.g., Andrews and Talbot, 2000; Scanlon, 1995, 2000; Steinberg, 2010, Weems, 2000) has shown, we are constructed as consumers in different ways by engaging in various sites of consumption, and this shows how we learn, for example, gendered, raced and classed consumer subjectivities. For instance, the female consumer has been discursively constructed as irrational, emotional and easy to trick, whimsical but passive, with narcissistic and vain properties (Sandlin and Maudlin, 2012). Constructions of the stereotyped female consumer are highly visible in the examined text and comply with product ads in mainstream media. Here, the student, 
through the marketisation of femininity, is shaped as rather irresponsible. Thus, student subjectivity is shaped as an entrepreneurial self and as a stereotyped female consumer. Through neoliberal discourse, consumption is feminised, where she is shaped as both free from responsibility and as responsible. What appears to contradict the double movement of autonomisation and responsibilisation promoted by neoliberalism can in fact be viewed as a resource in the operationalisation of the very same process. A femininisation of consumption is here adopted by the predominant discourses of marketisation and becomes both a starting point and a resource for the shaping of student subjectivity. This process can be understood through the contradictions associated with advanced liberal governing, particularly in relation to the notions of liberty and freedom. Because power is de-centred and individuals play an active role in governing themselves through self-regulation and self-correction, the freedom that is promoted by neoliberalism actually entails a process of autonomisation and responsibilisation (Rose, 1999b), unlike the conditions of an individual who is free from responsibility.

However, student femininities are also constructed through neoliberal discourse in additional ways. The process of shaping the neoliberal student subject is operationalised in the shaping of particular forms of femininity. One example is how the competitive student is partly shaped through a conception of feminine spaces as filled with rivalry. Another example is how certain consumption activities, as well as the bodily maintenance that these entail, can be understood in terms of responsibly shaping one's life through acts of choice - in this case, choices of a particular type of feminine consumption and feminine activities of bodily maintenance.

Moreover, in the text, blurred boundaries emerge through student femininity in different ways. Student femininity is shaped through particular consumption and bodily activities that work in boundary-crossing ways, and these activities are directly connected to sales and marketing activities that take place in social media - a platform where the lines between leisure and work, private and public, become porous. Furthermore, the conception of considering your vocation as your calling can be connected to typical female vocations, such as nursing (Andersson, 2002; Fejes and Nicoll, 2010). Therefore, one can say that the construction of a vocation as a calling is part of a process in which the specific vocation is constructed through femininity - a femininity that is partly shaped through exhortations that can be viewed through the notion of emotional labour (Hochschild, 1983). Moreover, the shaping of the successful student as happy shapes the student in ways that extend to her emotional life. This is an additional example of how student femininities are shaped in boundary-crossing ways. Here, normative constructions of femininity, which construct women as people who always ought to be emotionally available, are taken up by a discourse of marketisation.

Thus, a particular form of the gendered entrepreneurial self is shaped in this femininised educational context. The appropriate workstyle (see Du Gay, 1995) for the different aspects of the beauty business is shaped through particular forms of femininity promoted by neoliberalism, and vocational knowledge is constructed accordingly. These constructions contribute to the conditions established for students in these educational settings.

The responsibility for the students' success or failure is here shifted from the provider to the student, and the student is positioned as a consumer, seller and marketer of those beauty treatments that she learns how to offer. Thus, education is positioned as a process through which women are encouraged to become those who will promote the financial success of particular brands and beauty products. Thus, they become part of the market, or instruments of it, as they act to constitute and extend it. Construction of this specific vocational knowledge clearly cannot be decoupled from predominating marketisation discourses and gender norms, and it is most likely that this is also the case for other 
vocations. This study therefore highlights the importance of vocational research where the shaping of student subjectivity is taken into account, as well as the marketization of education. 


\section{References}

Andersson, Åsa. 2002. Ett högt och ädelt kall: Kalltankens betydelse för sjuksköterskeyrkets formering 1850-1930. Umeå: Umeå universitet.

Andrews, Maggie, and Mary Talbot. 2000. All the world and her husband: Women in Twentieth-century consumer culture. New York: Cassell.

Black, Paula. 2004. The beauty industry: gender, culture, pleasure, 1st ed., London: Routledge.

Boshier, Roger. 1973. "Educational participation and dropout: A theoretical model.” Adult Education 23(4): 255-282.

Cross, K. Patricia. 1981. Adults as learners: [increasing participation and facilitating learning]. 1st ed., 2. pr. San Francisco: Jossey-Bass.

Cookson, P. 1989. "Recruiting and retaining adult students: A practice perspective”, New Directions of Adult and Continuing Education, 1989(41): 3-11.

Davies, Bronwyn. 2006. "Subjectification: The relevance of Butler's analysis for education.” British Journal of Sociology of Education 27(4): 425-438.

Derrida, Jacques. 1991. A Derrida reader: between the blinds. New York, N.Y.: Columbia University Press.

Du Gay, Paul. 1995. Consumption and identity at work. London: Sage

Edwards, Tim. 1997. Men in the mirror: men's fashion, masculinity and consumer society. London: Cassell.

Edwards, Richard. 2002. "Mobilizing lifelong learning: governmentality in educational practices.” Journal of Education Policy 17(3): 353-365.

Evangelisti Allori, Paola, and Giuliana Garzone. ed. 2011. Discourse, identities and genres in corporate communication: sponsorship, advertising and organizational communication. Bern: Peter Lang.

Fejes, Andreas. 2010. "Discourses on employability: constituting the responsible citizen." Studies in Continuing Education 32(2): 89-102.

Fejes, Andreas, and Katherine Nicoll. 2010. “A vocational calling: Exploring a caring technology in elderly care.” Pedagogy, Culture \& Society 18(3): 353-370.

Foucault, Michel. 1980. Power/knowledge: selected interviews and other writings 19721977. 1. American ed. New York: Pantheon

Foucault, Michel. 1988. "Technologies of the self.” In Technologies of the self: A seminar with Michel Foucault, edited by L. Martin, H. Gutman, and P. Jutton, 16-24. Foucault, Michel. 1990. The history of sexuality. Vol. 1, The will to knowledge. Harmondsworth: Penguin.

Foucault, Michel. 2007. Security, territory, population: Lectures at the Collège de France 1977-1978. Houndmills, Basingstoke, Hampshire: Palgrave MacMillan.

Gimlin, Debra. 1996. "Pamela’s Place. Power and Negotiation in the Hair Salon.” Gender \& Society 10(5): 505-526.

Hochschild, Arlie Russell. 1983. The managed heart: commercialization of human feeling. Berkeley: Univ. of California Press.

Hult, Håkan. ed. 1997. Varför avstår arbetslösa från studieplats i kommunal vuxenutbildning?. Göteborg: Univ., Institutionen för pedagogik.

Hult, H., Larsson, S., Mäkitalo, Å., Olsson, L.-E., Paldanius, S. \& Thång, P.-O. (1997). Varför avstår arbetslösa från studieplats i kommunal vuxenutbildning?. Göteborgs universitet: Inst. för pedagogik. 
Jones, Geoffrey. 2010. Beauty imagined: a history of the global beauty industry. Oxford: Oxford University Press.

Lewis, Susan. 2003. "The integration of paid work and the rest of life. Is post-industrial work the new leisure?.” Leisure Studies 22(4): 343-345.

Little, Jo. 2013. "Pampering, well-being and women's bodies in the therapeutic spaces of the spa." Social \& Cultural Geography 14(1): 41-58.

Lundahl, Lisbeth. 2010. "Setting things right? Swedish Upper Secondary School Reform in a 40-year perspective.” European Journal of Education 45(1): 46-59.

Lundquist, Olof F. 1989. Studiestöd för vuxna: utveckling, utnyttjande, utfall. Göteborg: Diss. Göteborg: Univ.

McNay, Lois. 1992. Foucault and feminism: Power, gender and the self. Cambride: Polity Press.

Mäkitalo, Åsa. ed. 1997. Arbetslöshet eller utbildning?: om rekrytering av arbetslösa till komvux. Göteborg: Univ., Institutionen för pedagogik.

Nordberg, Marie. 2005. "'Det viktiga är en maskulin touche!' - Maskulinitet som konsumtionsvara i frisörbranschen.” Kulturella Perspektiv svensk etnologisk tidskrift 14(3).

Owens, Toni. 2000. Men on the move: a study of barriers to male participation in education and training initiatives. Dublin: Aontas.

Paldanius, Sam. 2002. Ointressets rationalitet: om svårigheter att rekrytera arbetslösa till vuxenstudier. Diss. Linköping: Univ.

Ramazanoglu, Caroline. ed. 1993. Up Against Foucault. Explorations of some tensions between Foucault and Feminism. London: Routledge.

Rose, Nikolas. 1996. "The death of the social? Re-figuring the territory of government." Economy and Society 25(3): 327-356.

Rose, Nikolas. 1999a. Powers of freedom: reframing political thought. Cambridge: Cambridge University Press.

Rose, Nikolas. 1999b. ”Inventiveness in politics.” Economy and Society 28(3): 467-493.

Rubenson, Kjell. 1975. Rekrytering till vuxenutbildning: en studie av kortutbildade yngre män. Diss. Göteborg: Univ.

Sánchez Abril, Patricia, Avner Levin, and Alissa Del Riego. 2012. ”Blurred Boundaries: Social Media, Privacy and the Twenty-First-Century Employee.” American Business Law Journal 49(1): 63-124.

Sandlin, Jennifer A., and Julie G. Maudlin. 2012. "Consuming pedagogies: Controlling images of women as consumers in popular culture.” Journal of Consumer Culture 12(2): $175-194$.

Scanlon, Jennifer. 1995. Inarticulate longings: The ladie's Home Journal, gender, and the promises of consumer culture. New York: Routledge.

Scanlon, Jennifer. ed. 2000. The gender and consumer culture reader. New York: New York University Press.

Scranton, Philip. ed. 2001. Beauty and business: commerce, gender, and culture in modern America. New York: Routledge.

Steinberg, S. R. 2010. "Barbie: The bitch can buy anything.” In Critical Pedagogies of consumption, edited by Sandlin, Jennifer A., and Peter McLaren, 69-82. New York: Routledge.

Waring, Amanda. 2008. "Health club use and 'lifestyle: exploring the boundaries between 
work and leisure.” Leisure Studies 27(3): 295-309.

Weems, Robert. 2000. "Consumerism and the construction of black female identity in twentieth-century America." In The gender and consumer culture reader, edited by Scanlon, Jennifer, 166-178. New York: New York University Press. 